\title{
A dimensão formadora do componente curricular Estágio Supervisionado, nos cursos de formação de professores
}

Arlete Vieira da Silva

Mestre em Ciências da Educação - UFPel; Professora de estágio supervisionado no curso de Letras - Departamento de Letras e Artes; Coordenadora do Colegiado do Curso de Letras Universidade Estadual de Santa Cruz. Ilhéus - BA [Brasil] arlete@uesc.br
Trata-se de uma reflexão sobre como atualmente se tem constituído a disciplina Estágio Supervisionado nos cursos de licenciatura e os encaminhamentos construídos de leituras (PICONEZ, 1998), de contatos etnográficos com a realidade da escola pública de educação básica e ainda de reflexões feitas com colegas do Fórum de Metodologia e Prática de Ensino dos cursos de licenciatura da Universidade Estadual de Santa Cruz (UESC). Para situar a disciplina Estágio Supervisionado foi preciso inicialmente constatar qual o papel da universidade como um dos centros de formação de educadores em nível superior e, logo refletir sobre os cursos de licenciatura e, como neles vêm se construindo a superação da dicotomia entre a teoria e a prática na formação de educadores.

Palavras-chave: Curso de licenciatura. Estágio supervisionado. Formação de educadores. 


\section{Primeiras palavras}

Considerando, inicialmente, que a universidade tem-se constituído como um dos principais centros de formação de professores em nível superior por meio de seus cursos de licenciatura convém rever qual o seu papel como instituição de ensino e, principalmente como formadora de educadores para a educação básica.

Sendo a universidade um dos centros de produção do conhecimento, que se configura na ciência, na tecnologia e na cultura, seu papel é de promover o avanço do saber e do saber fazer. No caso da formação de professores propriamente dito, além da construção do conhecimento, orienta sobre como se dará essa construção. Nesses cursos é possível afirmar que os componentes curriculares de formação pedagógica, as metodologias de ensino, as atividades de prática de ensino e os estágios supervisionados têm assumido este objetivo. Esta constatação procede quando verificamos que o embate com a realidade da escola de educação básica se dá apenas nessas disciplinas.

Entretanto, outro papel que a universidade deve assumir, segundo Alves (1995), é o de ser um espaço de invenção, de descoberta, de busca de novos conhecimentos, que se caracterizam na pesquisa, na socialização do saber. A disseminação desses novos conhecimentos se dá na forma de ensino, de pesquisa e de extensão, haja vista que por meio da suposta indissociabilidade desse tripé as ações da universidade corroboram as exigências de transformação da sociedade.

Diante desse papel desempenhado pela universidade e perseguindo a lógica de que os cursos de formação de professores são ofertados nas universidades, e ou em centros de educação, devemos, neste momento, dar "um salto" nesta reflexão e tratar especificamente dessa modalidade - curso de formação de professores - o que mais adiante deverá definir os papéis do componente curricular estágio supervisionado nestes cursos.

\section{Cursos de formação de professores}

É necessário, inicialmente, que os cursos de formação de professores priorizem preparar educadores-pesquisadores para atuar na escola e nos espaços alternativos educacionais. Pressupõe-se que esses cursos proporcionem uma sólida formação teórica em todas as atividades curriculares - nos conhecimentos específicos a serem ensinados pela escola básica e nos pedagógicos - tendo a pesquisa educacional como princípio embasador; Assim sendo, o profissional da educação deve ser capaz de apropriar, construir e reconstruir o conhecimento de forma que possa intervir na realidade, por meio de espaços educacionais, sempre em busca da consolidação da cidadania.

Pimenta e Lima (2004, p. 47) advertem para o papel da universidade "[...] como espaço formativo da docência, uma vez que não é simples formar para o exercício da cidadania de qualidade e que a pesquisa é o caminho metodológico para essa formação."

A formação do educador deve ser de caráter amplo, garantindo ao "formado" o domínio e compreensão da realidade de seu tempo, demonstrando uma consciência crítica e capacidade de atuação como agente transformador do contexto em que se insere.

A superação da possível dicotomia entre a teoria e prática deve constituir-se como concepção de que o cotidiano da realidade escolar paralelamente aos conhecimentos específicos caracteriza a 
formação nesses cursos. Para tanto, sua formação pedagógica deve ser iniciada nos primeiros períodos, corroborando com certeza de que o saber docente não se constrói por complementação (PICONÊZ, 1998), mas é um processo construtivo que ocorre pela incorporação de conhecimentos e habilidades pedagógicas; nesse contexto, a pesquisa pedagógica (ANDRÉ, 1999) deve ser instituída como componente transversal curricular ao longo do curso, o que contribuirá para a formação do professor críticoreflexivo, estimulando a atitude investigativa como condição inerente ao exercício do magistério.

Entretanto, é preciso ressaltar que na forma rígida como tem se caracterizado atualmente o currículo dos cursos de formação de professores, percebe-se que o componente curricular estágio supervisionado tem sido um dos únicos, senão o único, responsável em provocar um embate com a realidade da escola de educação básica (PICONÊZ, 1998), por meio do exercício da docência e ou outras atividades que caracterizam sua atuação.

\section{0 componente curricular estágio supervisionado nos cursos de formação de professores}

A prática de ensino e o estágio supervisionado, previstos pelos órgãos superiores oficiais por meio da Lei de Diretrizes e Bases da Educação Nacional (LDB EN) e Resoluções ${ }^{1}$ como componentes curriculares, merecem um destaque especial, pois não poderão se constituir numa prática burocrática e alienada e cumpridora apenas das normas legais quanto aos seus objetivos e a sua carga horária. Há de se constatar que a legislação atual corrobora com o que algumas autoras (PIMENTA, LIMA, 2004), têm denominado de neotecnicismo educacional quando propõem como objetivos a instrumentalização, o domínio de técnicas como possibilidade do exercício da docência com qualidade na educação básica. Não é possível pressupor que o aumento de carga horária do componente curricular e o treinamento de métodos e técnicas a serem aplicadas assegurem a qualidade do ensino na educação básica.

A concepção acerca do papel do estágio supervisionado se coaduna com a conotação de uma prática de ensino e estágios supervisionados articulados à pesquisa do cotidiano da escola e todas as suas nuances e idiossincrasias, para que o aluno/estagiário vivencie a realidade educacional como um todo. Esses componentes curriculares deverão se pautar nas vivências reflexivas críticas da gestão e da organização escolar, na dinâmica da sala de aula, na análise curricular e nos processos avaliativos com base nos saberes necessários à prática educativa (FREIRE, 1989), ao educador como um intelectual reflexivo (ZEICHNER, 2001, ALARCÃO, 2002, NÓVOA, 1997) e militante crítico diante das presenças e ou ausências de políticas públicas para a educação.

Aquilo que a legislação vai chamar de competências e, diga-se, caracterizado num teor "utilitário-pedagógico", se concebe como competências profissionais que serão construídas processualmente com práticas de ação e de reflexão na e sobre a prática - aqui concebida na vivência na escola, por exemplo, Assim, é necessário que as bases curriculares dos cursos de formação de professores se articulem na perspectiva metodológica de ação-reflexão-ação e/ou reflexão-ação-reflexão (FREIRE, 1989). Inevitavelmente, em primeira perspectiva, essas categorias freirianas são inerentes à educação e representam uma das possibilidades de mudança e transformação da realidade educacional pela presença desses profissionais na educação básica e, numa outra perspectiva mais ampla, a dimensão do 
ensino, da pesquisa e da extensão, um dos papéis da universidade mencionado no início deste texto.

Ratificando e encaminhando propostas é possível afirmar que por meio de atividades como observação, entrevistas, diários de aulas, participação em projetos, atividades complementares, inserções na comunidade com o objetivo de conhecer, identificando, e ou investigar a realidade da escola pública ou especificamente de um dos aspectos do processo de ensino e aprendizagem, o aluno de um curso de formação de professores assume a postura de pesquisador, pois se torna um investigador de determinada realidade e/ou um ou mais aspectos do cotidiano da escola.

Com esses dados observados e coletados as aulas na universidade e os encontros coletivos com os colegas, futuros professores serão os momentos apropriados de reflexão, de análise da realidade observada e, consequentemente de organização e ou de re-organização de sua prática atual como alunoprofessor ou como aluno apenas. Nesta perspectiva, certamente sua ação considerará a ação primeira e a reflexão feita.

Pode-se concluir, portanto, que o Estágio Supervisionado é um componente curricular muito importante em uma proposta curricular de um curso de formação de professores em razão dos seguintes fatores:

- Constitui-se de uma possibilidade de superar a dicotomia entre a teoria e a prática quando seus pressupostos são um embate com a realidade do ensino da escola pública de educação básica;

- É possibilidade de acesso à cultura escolar, aos saberes docentes e aos conhecimentos específicos sobre o fazer pedagógico, a identidade docente e a formação profissional.
- Supera a indissociabilidade entre ensino, pesquisa e extensão, quando sua proposta metodológica se caracteriza em atividades de investigação, de elaboração e re-elaboração de novos saberes, e de intervenções na comunidade escolar;

- Prepara o profissional para o exercício da prática do trabalho, da cidadania e da vida cultural;

- Proporciona a atualização sobre procedimentos e de aspectos diversos do processo de ensino e aprendizagem e o conhecimento de novas linguagens educacionais;

- Estabelece o diálogo entre a área educacional e as demais áreas do conhecimento;

- Identifica novas tecnologias de informação e comunicação, adequando-as à realidade educacional de sua inserção.

Muitos outros fatores ainda podem ser elencados, entretanto, há também a necessidade de tecer considerações a serem alteradas nas propostas curriculares de muitos cursos de formação de professores. Tem sido conferido ao componente curricular estágio supervisionado um caráter complementar ou mesmo suplementar ou ainda nas palavras de Azevedo (1980) uma teoria posta no início do curso e uma prática no final, caracteriza um granfinale ou evidencia mais claramente a dicotomia existente entre a teoria e a prática num curso que é de formação de educadores. A questão que precisa ser posta é que não é o caso de aumentar a prática em detrimento da teoria ou vice-versa, mas adotarmos uma nova forma de produzir conhecimento no interior dos cursos de licenciatura. A pesquisa educacional pode e deve ser uma resposta (FÁVERO, 1995).

Outra consideração está na organização do programa da disciplina ou na proposta para o semes- 
tre. Note-se que a falta de investigação da realidade em todas as suas nuances (pedagógicas, culturais etc.) resultam em propostas isoladas, fragmentadas e que não vislumbram as exigências próprias da comunidade escolar. Há casos em que as orientações desse componente têm sido dirigidas em razão de atividades programadas a priori sem que tenham surgido das discussões entre educadores e educandos no cotidiano da sala de aula, da escola e da comunidade. O conhecimento da realidade escolar, assim, tende a não refletir uma prática criativa e transformadora e não possibilita a reconstrução ou a definição de teorias que sustentem o trabalho do futuro professor.

Há um ínterim neste aspecto que é necessário destacar, pois tem se constituído um equívoco nas discussões acerca do trabalho do professor da escola pública, ou seja, "usamos" o conhecimento da realidade escolar como denúncia de supostos "erros" da escola e da prática de professores colaboradores dos(as) estagiários(as) sem buscar alternativas metodológicas realmente transformadoras para a superação desses supostos "erros". Às vezes, fatores externos e internos, como a formação do educador, a infra-estrutura da escola etc. poderiam ser considerados (e não determinados) como variáveis para aquela realidade.

Na literatura atual (PICONÊZ, 1998), o componente curricular estágio supervisionado aparece, não raro, mais com recomendações do que com reflexões sobre a formação de professores. E paralelo às recomendações, muitas críticas sobre sua inadequação e pouca contribuição no preparo de professores para a educação básica.

\section{$4 \quad$ Concluindo}

No nosso entendimento o componente curricular estágio supervisionado deve ter como pres- suposto a "preocupação" em definir claramente a concepção de educador e de educação em suas relações político, sociais, culturais e artísticas, tendo presente a conjuntura da época e as condições profissionais da categoria docente. $\mathrm{O}$ educador de um curso de formação desse componente será o orientador que faz a ponte entre a os saberes docentes e os culturais, entre os conteúdos específicos e os temas transversais, entre a metodologia e a sua aplicabilidade, entre a teoria e a prática, entre as possibilidades e as mudanças concretas, numa concepção de que o ato educativo é político, e pode ser transformador de uma realidade social (FREIRE, 1989) - em última instância, um dos papéis da universidade.

\section{The fomative dimension of curricular component Supervised Practical Training in courses of educators training}

This paper is a reflection about how the subject Supervised Practical Training is constituted nowadays, in the courses of teachers' formation as well as proceeding constructed from reading (Piconez 1998), from ethnographic contacts with the reality of public school of basic education and also related to reflections on the Methodology and Teaching Practice Forum of the courses of Universidade Estadual de Santa Cruz (UESC). In order to situate the discipline Supervised Practical Training, previously, was necessary verifying the university's role as one of the centers of educators formation in the higher education, and soon reflecting the courses of teachers' training about how they have been overcoming the dichotomy between theory and practice taking into account the formation of educators.

Key words: Educators' formation. Supervised practical training. Teacher's training course 
Nota

1 LDB EN no 9394/96 e Resolução no 01 e no 02 de 18 e 19 de fevereiro de 2001, respectivamente. Tratam das diretrizes curriculares para os cursos de formação de educadores e da carga horária mínima obrigatória.

\section{Referências}

ALARCÃO, I. Professor reflexivo no Brasil. Gênese e crítica de um conceito. São Paulo: Editora Cortês, 2002.

ALVES, N. (org.). Formação de professores pensar e fazer. 3. ed. São Paulo: Cortez, 1995. (Questões da nossa época).

AZEVEDO, L. M. F. de. O estágio supervisionado: uma análise crítica. Dissertação (Mestrado em Educação)Pontifícia Universidade Católica do Rio de Janeiro, Rio de Janeiro, 1980.

FÁVERO, M. de L. A. de. Universidade e estágio curricular: subsídios para discussão. In: ALVES, N. Formação de professores: pensar e fazer. 3. ed. São Paulo: Cortez, 1995. (Questões da nossa época).

FREIRE, P. Educação e mudança. $7^{\mathrm{a}}$. ed. São Paulo: Cortez, 198789.
NÓVOA, A. Vida de professores. Portugal: Ediporto, 1997.

PICONEZ, S. A prática de ensino e o estágio supervisionado. 3. ed. Campinas: Papirus, 1998.

PIMENTA, S. G.; LIMA, M. S. L. Estágio e docência. São Paulo: Cortez, 2004.

SILVA, A. V. da (Org.). A construção da prática de ensino sob a forma de estágio supervisionado do curso de letras. Ilhéus: UESC, 1999. (Documento). Estágio curricular supervisionado no curso de licenciatura: momentos de vivência da profissão professor nas escolas de educação básica. Revista Virtual Espaço Acadêmico, n. 73, jun. 2007. Disponível em: <www.espacoacademico.com.br>.

A contribuição dos saberes/conteúdos do componente estágio supervisionado na vivência da prática na escola de educação básica. Projeto de pesquisa - em andamento. Aprovado na $75^{\mathrm{a}}$ reunião do CONSEPE/UESC, 17 de dezembro de 2008.

ZEICHNER, K. M. Para além da divisão de professorpesquisador e professor-acadêmico. In GERALGI, Corinta (org.). Cartografias do Trabalho Docente. Professor(a) Pesquisador(a). Campinas, SP: Mercado das Letras, 2001. recebido em jul. 2009 / aprovado em ago. 2009

Para referenciar este texto:

SILVA, A. V. da. A dimensão formadora do componente curricular Estágio Supervisionado, nos cursos de formação de professores. Dialogia, São Paulo, v. 8, n. 1, p. 103-108, 2009.

Dialogia, São Paulo, v. 8, n. 1, p. 103-108, 2009. 